


\section{Article Artículo Paper La clínica social d'Iràklion 4 (Grècia): un exemple de resistència i solidaritat davant la indefensió neoliberal}

\section{Jordi Alzina}

jordialzina@gmail.com

\section{Resum}

El present article pretén constatar la correlació existent entre l'aplicació de polítiques neoliberals els darrers cincs anys a Grècia i la seva afectació en la salut de les persones, en el que entenc com l'extensió d'un procés d'indefensió jurídica, que intenta atenuar-se mitjançant la solidaritat del propis membres de la societat afectada. Per explicitar aquesta hipòtesi, parteixo del meu treball de camp a l'illa de Creta els darrers anys, i concretament en el desenvolupament i la creació de la clínica social d'Iràklion.

Paraules clau: Austeritat, neoliberalisme, salut, atenció sanitària, indefensió, Grècia.

\section{Summary}

This article aims to verify the correlation between the application of neoliberal policies in the last five years in Greece and their effects on the health of people. I understand this to be the extension of a process of 
legal defenselessness. To clarify my hypothesis, I use part of my fieldwork on the island of Crete in recent years, and particularly in the development and creation of the community health centre in Heraklion.

Key words: Austerity, neoliberalism, health, healthcare, hopelessness, Greece. 


\section{Introducció}

«Hem correspost a la crisi econòmica, però no hem dominat la crisi social», (Dominique Strass Khan, director de l'FMI a France 2, febrer 2011)

Dins el context de recessió mundial que s'inicià a finals del 2008 amb el frau de Lehman Brothers, Grècia fou el primer país europeu on aquesta crisi es manifestà de forma més ràpida i també dramàtica. Les debilitats estructurals de l'economia grega, combinat amb un elevat deute públic i una partitocràcia que des de l'any 1974 s'havia anat alternant en el poder, propiciaren la intervenció del país hel-lènic. E1 2 de maig del 2010, la Unió Europea, el Fons Monetari Internacional i el Banc Central Europeu, més coneguts com a Troika, imposaren a canvi de l'anomenat rescat un conjunt de mesures de caràcter neoliberal ${ }^{1}$, encaminades entre d'altres aspectes, a la privatització dels serveis públics, la venda de les propietats de l'estat i una retallada general en la despesa estatal. Cinc anys després, crec que podem establir de forma clara, una correlació directa d'aquestes polítiques i els seus efectes perniciosos sobre la salut de les persones, i com la ciutadania, davant la pèrdua de drets fonamentals com l'assistència sanitària universal ${ }^{2}$, busca mecanismes per tal d'aturar aquest retrocés.

Davant la impossibilitat d'abastar tot el territori grec i l'espai limitat d'aquesta publicació, centraré la defensa de la meva hipòtesi a l'illa de Creta, basant-me en el meu treball de camp previ i la seva fonamentació teòrica.

\section{Metodologia}

Entre els anys 2006 i 2013 vaig viure a Creta (l'illa més gran de Grècia), i els anys 2014 i 2015 i vaig passar tot l'estiu. Per tant vaig poder copsar en primera persona $\underline{3}$ els canvis que s'anaren imposant a la població i l'afectació que aquestes polítiques han tingut sobre la po-

1. Un rescat que s'ha repetit fins a tres cops per mostrar-se insuficient.

2. A Grècia, segons les darreres dades, hi ha més d'un milió de persones sense accés a la sanitat pública. Tal com ja va publicar en el seu moment el Dr. David Stuckler de la universitat d'Oxford i exposar les dades de les seves investigacions a Grècia a la revista The Lancet, on denunciava els efectes de les retallades sobre la salut de les persones. L'any 2015 aquesta investigació es va publicar en format llibre, sota el títol «The body economic: Why Austerity Kills». 
blació illenca, apart d'obtenir un coneixement ${ }^{3}$ directe gràcies al treball de camp iniciat per a la meva recerca doctoral iniciada l'any 2011, tot un seguit de dades que vaig anar apuntant en el meu diari de camp. També, entre d'altres aspectes relacionats amb la temàtica presentada, entre l'any 2011 i 2013 vaig recollir totes les notícies aparegudes en la premsa escrita local relacionades amb els suïcidis, vaig consultar altres mitjans nacionals i internacionals que feien referència a l'efecte de les polítiques neoliberals en la salut de les persones, com també la bibliografia relacionada amb la meva hipòtesi, encara que en l'àmbit grec, la seva producció intel-lectual encara és molt minsa. Altrament, durant l'estiu del 2015, vaig poder fer treball de camp a la clínica social d'Iràklion, observar el seu funcionament, i fer un seguit d'entrevistes a metges i voluntaris que treballen pel seu bon funcionament.

\section{Marc teòric}

\subsection{Aproximació des de la medicina social}

Recordava recentment el catedràtic d'economia Vicenç Navarro en el seu blog al diari el Público (15/12/2015), com cada vegada hi ha una acord més estès entre un sector dels economistes més coneguts a nivell internacional (Joseph Stiglitz (2015) y Paul Krugman (2012), entre d'altres), en assenyalar les polítiques neoliberals com la causa d'una de les majors recessions que es coneixen entre els segles XX i XXI. Però tanmateix, encara no són suficients els treballs referents a l'impacte d'aquestes polítiques sobre la salut de les persones i, sobretot, sobre les classes més desvalgudes, les classes populars ${ }^{4}$. Unes reflexions que em serveixen per enllaçar amb el marc teòric que proposo per tal de defensar la meva hipòtesi al respecte. És a dir, com a través d'aquestes polítiques neoliberals estem sotmesos cada cop més a un procés d'indefensió, en la mesura que hem de renunciar als nostres drets com a ciutadans en nom de certa recuperació econòmica, i, com a tal, la salut o el seu accés (dret), es veuria directament afectat per l'impacte que suposa l'aplicació d'aquestes polítiques. ${ }^{4}$

3. En aquest sentit, em remeto al concepte d'habitus de Pierre Bordieu, per assenyalar la meva predisposició i coneixement a l'hora d'estudiar la societat cretenca. No només són els anys viscuts o l'aprenentatge de la llengua i el seu dialecte (sempre inacabable), sinó també el fet que la meva dona sigui originària de l'illa grega, també m’ha donat un seguit de coneixements que segurament no hauria obtingut de cap altre manera o hagués tardat molt a obtenir-los.

4. "El neoliberalismo mata y pone enfermas a las clases populares": http://blogs.publico.es/vicenc-navarro/2015/12/14/el-neoliberalismo-mata-y-pone-enfermas-a-las-clases-populares/ 
Des de la fundació de l'anomenada medicina social (mitjans del segle XIX), hi ha una nissaga d'estudis i elaboracions teòriques que des de Virchow, Engels o Durkheim, i fins a Warner, Black, Rosen o Sudnow, insisteixen en atorgar a les condicions de l'entorn social, i a l'evolució dels cicles econòmics, una centralitat a l'hora de donar compte dels estats de salut i benestar de les poblacions. Incloent- $\mathrm{t}^{\prime} \mathrm{hi}^{5}$ també la salut i la malaltia mental, i com a derivació lògica, les fluctuacions de les consultes psiquiàtriques i l'índex de suïcidis.

És en aquest darrer tema on el cas grec, o més aviat cretenc, es mostraria encara més dramàtic, ja que de que tots els indicadors epidemiològics que es veuen afectats pels cicles econòmics decreixents, m`interessa destacar aquí, l'evolució de la taxa de suïcidis, per ser aquest altament preocupant; un fenomen que em remet inevitablement al concepte dranomia d'Émile Durkheim. L'autor francès assenyala ja una primera definició d'aquest concepte a "La división del trabajo social" (1987 (1893)), entesa aquí com una ruptura de la solidaritat, on l'anòmia és l'expressió d'una crisi d'individualització, a la qual ens hauria conduït el desenvolupament industrial de les forces productives als països de l'Europa occidental, amb el seu corresponent model d'organització del treball (Capitalisme) i la seva corresponent estructura cultural (Modernitat). Parlem doncs, d'una societat hiperindividualitzada, especialitzada, i atomitzada, a l'interior de la qual l'individu és radicalment substituible, i per tant prescindible, dins un sistema capitalista caracteritzat per la seva anomia ${ }^{6}$.

Aquest és sens dubte un punt important, ja que ens permet definir les societats que sorgeixen de la modernitat com a inherentment anòmiques i estructuralment poc cohesionades ${ }^{7}$.

5. Una de les obligacions que el govern grec va haver d'assumir per tal d'obtenir el famós rescat, va ser acceptar sota el paraigua de l'anomenada estabilitat pressupostària, que el pagament de la deuda pública fos prioritària davant qualsevol altre inversió o pagament de l'estat. D'aquesta manera, les necessitats de la població quedàven totalment posades en un segon pla. Un principi que atacava directament els principis de la Constitució grega vigent, però que tot i ser inconstitucional va ser aprovada pel seu govern. A l'estat español es va reformar primer la constitució en el seu article 135, per tal d'evitar aquesta contradicció. Uns efectes que em remeten al concepte d'immoralitat major, del sociòleg estatunidenc Wright Mills (1957) i el seu estudi sobre el cinisme neoliberal sorgit després de la II Guerra Mundial, on el teòric neomarxista, estudia el funcionament de les elits de poder sorgides en aquest context, i que segons el meu criteri no han fet més que perpetuar-se fins a l'actualitat.

6. La sociologia francesa ha continuat replantejant-se (sobretot des de l'inici del segon mil·leni) la seva teorització arrel de l'aparició de noves formes d'organitació laboral, on el suïcidi ha continuat copant el llistat de la tràgica llista de conseqüències del nous models de gestió del treball. Casos com els mediàtics suïcidis dels treballadors de France Telecom l'any 2009, varen servir per qüestionar aquests nous models de forma pública. En aquesta línia, es pot consultar el següent article de Pino Ferraris (21/7/2010): “Los suicidios en el centro de trabajo: el caso de France Télécom. http:// www.hobest.es/blog/los-suicidios-en-el-centro-de-trabajo-el-caso-de-france-telecom-pino-ferraris"

7. La crisi també actuaria com a detonant d'aquestes formes de cohesió. 
Però serà en el "Suicidio" (1992 (1897)), on Durkheim elabori un concepte d'anomia, molt més útil, per a travar explicacions específiques sobre els motius concrets que indueixen als individus al suïcidi. Segons aquesta segona elaboració, Durkheim explica el «suïcidi anòmic» en termes d'inadequació i desajustos entre medis i finalitats socials, atenent especialment al seu impacte sobre els actors socials individuals. La inestabilitat produïda pels canvis de valors i les transformacions econòmiques i socials generen inseguretat i desorientació individual, assenyalant fins a quin punt, l'home, només pot viure si les seves necessitats es troben en harmonia amb els seus mitjans.

Des d'aquest punt de vista l'ús del terme «necessitat» no es pot limitar a una accepció de la noció associada exclusivament a les necessitats econòmiques vinculades a la supervivència orgànica. Probablement Durkheim s'està referint a una economia de les necessitats, entre les quals s'inclouen les de caràcter simbòlic, és a dir, aquelles relacionades amb la supervivència de l'ésser social. En aquest sentit, el suïcidi podria ser entès com una resposta "individual” davant la impossibilitat - per part de l'actor social- de desenvolupar les funcions assignades en el seu entorn social ${ }^{8}$.

I és aquí on rau la importància del terme «mitjans», que en aquest cas, podríem traduir per «recursos», doncs el que Durkheim ens assenyala és com en situacions de crisi, el paper de la societat com a reguladora de recursos socials esdevé ineficaç i inadequat, i com a conseqüència, els actors es troben desorientats.

Seguint amb el mateix concepte, és molt interessant la perspectiva que adopta Robert Merton (2003) 50 anys després, i al parlar d'anomia es refereix a una separació, entre els objectius culturals i l'accés de certs sectors als mitjans necessaris per aconseguir aquests objectius. Un concepte que enllaçaria perfectament amb la definició de Lévi-Strauss a $L a$ identidad (1981), on ens assenyala com l'individu sense mitjans no és una entitat viable.

8. Les dades recollides a Creta ens mostren com el suïcidi té una incidència important entre els homes de mitjana edat que no poden assumir les seves funcions socials que s'espera d'ells, com per exemple, ser cap de família. Una aproximació que una de les meves informants, psiquiatre de professió a l'illa, també em va confirmar. Són encara pocs els estudis elaborats des del propi país hel·lènic que abordin la temàtica aquí presentada. Una de les publicacions que més han trascendit sobre la qüestió va publicar-se l'any 2014 sota l'autoria de Mixalis G. Madianós i Marina Oikonómou, dos psiquiatres. El titol n’era prou evocador: "Crisi grega, depressió nacional i exercicis de supervivència”. 


\subsection{El dret a la salut}

"Em treuen la vida si em treuen els mitjans pels quals visc" Shylock, El mercader de Venècia (W. Shakespeare)

Un cop ha quedat explicat que la crisi financera té uns responsables, i quina és la seva afectació sobre la vida i també la mort de les persones, ens queda fonamentar en el Dret aquestes actuacions.

És en aquest sentit que lıantropologia jurídica ens ofereix tota una sèrie de conceptes analítics que ens permeten elaborar i fonamentar aquesta qüestió. Principalment ens interessen les aportacions lligades al que es coneix com a justícia vindicatòria.

La justícia vindicatòria és un procediment que reconeix una ofensa i que crea sempre l'obligació d'esmenar-la, sense perjudici de la seva vindicació cruenta que pot concórrer amb l'esmena i amb una tributació a l'autoritat judicial.

La reconciliació pura, sense esmena, i l'esmena amb reconciliació, sense retribució cruenta, són els procediments típics de la justícia vindicatòria (Terradas 2012).

La teorització del concepte va ser encetat sobretot per Antonio Pigliaru i Raymond Verdier, tot i que també la trobem en l'obra de Fustel de Coulanges sobre les institucions polítiques de la França antiga, i en estudiosos del dret antic i medieval, encara que tot sovint s'interpreta aquest com a "predret" i s'observa la reticència a acceptar institucions de dret públic i processos comparables als enjudiciaments dels moderns Estats de dret (Terradas 2008).

En primer lloc l'estudi antropològic de la justícia vindicatòria tracta de restablir la racionalitat d'un ordenament jurídic, la seva lògica, amb les seves normes i procediments a la societat on es desenvolupa. Uns estudis que han demostrat que la justícia vindicatòria queda molt lluny dels elements irracionals o del sotmetiment de la venjança.

En el nostre ordenament jurídic, la moral cristiana, i els valors cívics associats a l'Estat de dret rebutgen la venjança, perquè consideren que no existeix ni en la legislació ni en qual- 
sevol procés legal i legítim. En general no s'admet que la venjança és un desig o sentiment que pot existir tant en una llei com en un judici. Basicament perquè la venjança se situa en l'àmbit de la irracionalitat. En canvi, la justícia vindicatòria admet la venjança com un sentiment humà inevitable, significat i viscut socialment, necessari i en molts casos com a deure moral. En contraposició al que entenem per venjança en la nostra cultura, la justícia vindicatòria intenta de reconèixer, canalitzar, transformar o legitimar determinats tipus de venjança, tot i que en cap cas, no s'admet, la represàlia, la rancúnia i la contraofensa descontrolada. Des del punt de vista vindicatori, la venjança és abans que res un deure moral, al mateix temps que una obligació social i jurídica, encaminades i prescrites per una autoritat judicial del llinatge, del clan o del reialme. Aquest sentiment de venjança es reconeix associat primerament a la indefensió, és a dir, quan es dóna una afronta, una ofensa sense defensa possible. És en aquest moment, on la venjança, si no compte amb cap autoritat judicial, es possible per ella mateixa, és legitima; tot i que en general, es canalitza a través d'una autoritat judicial que pot transformar-la en composició, o bé, legitimar-la amb un veredicte judicial ${ }^{9}$.

En el cas del registre penal, l'homicidi es presenta com a delicte amb una construcció que estableix una equació entre la gravetat d'un fet i una pena corresponent, tot atribuint la part responsable i les seves conseqüències indemnitzadores o reparadores a favor de la part ofesa, si es donés el cas. En el registre vindicatori se situa en primer pla el que anomenem la víctima, la part ofesa, que en l'ordenament vindicatori té una facultat instructora parcial i que a més compte amb tota la solidaritat social que comporta la seva situació, és a dir, en contraposició al nostre sistema jurídic no resta quasi mai sola. Com veiem doncs, en el procediment vindicatori la part ofesa gaudeix d'un protagonisme i d'un empoderament jurídic i moral, que en el nostre context es pretén aconseguir amb l'ajut de diversos professionals, un fet que evidencia encara més, la situació de sol-litud en la qual es troba la part ofesa.

Dins l'ambit de la justícia vindicatòria, moralment i juridicialment un homicidi involuntari està al límit de la possibilitat composicional, però quan aquest és voluntari, intencionat, llavors es pot acudir a la composició, i es requereix un esforç que recau tant en el dret com en la moral o la religió.

9. Com veiem, l'estudi des de l'antropologia jurídica de la justícia vindicatòria ens apropa al coneixement de les cultures jurídiques de la major part de la humanitat, que en la seva majoria i en gran part, no han estat regides pels ordenaments caracteritzats per la divisió civil/penal del dret i que constitueixen el que es reconeix com l'Estat de dret modern. 
L'abast del significat de l'ofensa per a la justícia vindicatòria, veiem que es cabdal, i que es tenen en compte totes les circumstàncies que fan la vida social de la persona, que la mantenen en relacions de reciprocitat, autoritat i solidaritat. Hi ha una valoració del dany moral realitzat segons la persona i el cas, centrant-se en l'ofensa i no tant en el delicte.

En aquest sentit, la justícia vindicatòria busca esmenar els danys comesos contra la vida de les persones: "Els danys i perjudicis materials o patrimonials obtindran consideració a partir del seu significat d'atemptat contra aquesta vida, no segons el valor de mercat, posem per cas, dels bens afectats" (Terradas 2012:12) Com veiem, partir de la idea moral i jurídica d'ofensa, es contraposa o difereix plenament d'una cultura jurídica en la que l'Estat de dret es fonamenta amb la divisió entre el dret civil i el penal, el qual en essència separa el deure i l'obligació de l'ofensa i la culpa. Per tant, a la nostra societat, podem entendre que, la responsabilitat indemnitzadora estimada segons el valor de la persona, és dóna com una perversió.

La diferència social bàsica però entre aquestes dues cultures jurídiques, rau en la responsabilitat individual del nostra sistema i la col-lectiva, habitualment corporativa, de les societats amb justícia vindicatòria. Aquestes diferències estant essent observades recentment per diferents autors al plantejar les seves crítiques al model socioeconòmic actual, encarnat pel neoliberalisme, que sota el paraigües de les lleis del mercat imposa restriccions de tot tipus allà on fica la mà, tal com apuntava en el cas cretenc.

En aquest sentit, en un article publicat a l'agenda llatinoamericana 2013 titulat "Buidament de democràcia i genocidis econòmics"10, Franz Hinkelemert, resumeix també amb una cita el que hem anant plantejant fins ara: "Prendre al proïsme els mitjans de subsistència és matar-lo, i privar de sou un treballador és assassinar-lo" (Eclesiàstic 34, 22). Un text, que segons l'autor va ser un dels inspiradors perquè Bartolome de las Casas es convertís amb un dels defensors dels indígenes d'Amèrica, davant l'etnocidi que es produeix durant el segle XVI en el continent, i que ha explicitat Tzevan Todorov en les seves investigacions al voltant de la Conquesta d'Amèrica. Todorov (1987), ens mostra com molts indígenes es deixaven morir o se suïcidaven directament, davant la impossibilitat

10. "Buidament de la democràcia i genocidis econòmics": http://www.servicioskoinonia.org/agenda/archivo/catalan/obra.php?ncodigo=740. 
d'adaptar-se a un nou medi, al canvi de les condicions de vida, la minva dels recursos i el trencament amb els seus lligams afectius (de parentiu o dins el propi grup), en definitiva no s'adaptaven a un sistema que actuava contra la seva pròpia vida.

\section{Context actual}

\subsection{Els efectes negatius en la salut de les persones}

L'any 2012, el diari E1 País encapçalava una notícia, amb un titular ben explícit: «E1 FMI pide bajar pensiones por "el riesgo de que la gente viva más de lo esperado» ${ }^{11}$. Un titular que reflexava sense eufemismes la ideologia imperant en el si d'aquesta organització, i que servia per il·lustrar les paraules de la nova directora d'aquesta organització en una recent reunió a la seva seu a Nova York. Les seves propostes també eren ben clares: que l'edat de jubilació s'adeqüi a l'esperança de vida, retallada de les prestacions, augment de les cotitzacions, i que les asseguradores privades cobreixin el cost de longevitat. Un seguit de mesures que denotaven la preocupació dels seus màxims dirigents davant l'augment de l'esperança de vida a escala mundial, però sobretot en els països on l'estat del benestar encara assegura una sèrie de prestacions perquè aquesta etapa de la vida sigui prou profitosa.

De fet, els dirigents d'aquesta organització feien palès allò que ja era evident: «Tots els països que han estat intervinguts per l'FMI han tingut una disminució de la seva esperança de vida entre 5 i 10 anys, amb unes mesures que afecten directament la vida dels ciutadans.» Així de contundent es mostrava un dels metges més reputats de Grècia, el neurocirurgià P. Papanikolau, en el documental Debtocracy, centrat en la crisi grega i estrenat l'any 2010 a la xarxa. Dades que confirmaven els informes de l'ONG grega Metges del Món, quan parlaven de crisi humanitària al centre d'Atenes ${ }^{12}$, i destacaven situacions no gaire diferents de les de l'anomenat Tercer Món. En un moment, on als hospitals del país, començava a ser preocupant la falta d'elements bàsics com sabó, mantes o recipients

11. Unes declaracions que ens remeten al concepte de biopoder definit per Michel Focault a "La Voluntad de Saber" (2006), per tal d'assenyalar la pràctica dels estats moderns de "explotar numerosas y diversas técnicas para subyugar los cuerpos y controlar la población".

12. "The access of the poor and socially excluded groups living in the center of Athens, in the sectors of health, education and labor" (2011): http://mdmgreece.gr/en/research-study/. 
per a l'anàlisi d'orina, entre altres. I la deixadesa en el manteniment de les infraestructures internes era realment greu. Uns extrems que no feien més que agreujar la precària sanitat grega, imbuïda des de fa dècades en la pràctica de la corrupció, en el que popularment es coneix com a fakelaki (sobret en grec), i que ha generat grans escàndols els últims anys.

A més a més, la desocupació, el deute i la pobresa han afectat directament l'esperança de la població grega d'un futur millor; l'augment dels suïcidis (i també dels avortaments), durant els últims anys, no en deixa dubte: "We found a clear increase in suicides among persons of working age, coinciding with austerity measures. These findings corroborate concerns that increased suicide risk in Greece is a health hazard associated with austerity measures"13. El febrer de l'any 2012, segons l'estadística que publicava l'Eurostat, més d'un de cada quatre grecs vivia sota l'amenaça de la pobresa i l'exclusió social ${ }^{14}$.

En un fragment del meu diari de camp, el 26 d'abril del 2012, apuntava el següent: «Divendres passat un home d'Iràklion de 54 anys, comptable i sense problemes econòmics aparents, va decidir posar fi a la seva vida. En una nota deia: "No puc viure una vida que ens imposen." Dissabte era un mestre d'escola i sindicalista, Savvas Metikidis de 45 anys, qui decidia fer el mateix, en una acció carregada de contingut polític, tal com demostra la carta que deixà amb la clara voluntat de remoure les consciències dels seus conciutadans, tot emulant l'acció que havia realitzat, ara fa un mes, Dimitri Xristoula, un jubilat de 77 anys, que just abans de disparar-se al cap a la plaça Sintagma d'Atenes, situada davant mateix del parlament, cridava: "No em suïcido, em maten!" I abans-d'ahir era un jove doctor en geologia de la universitat d'Atenes, que s'havia quedat sense plaça gràcies a les retallades... i la sagnia, continua oberta».

A Grècia, segons les fonts oficials, l'any 2011 van suïcidar-se més de 1.700 persones, una xifra que representa un augment del $40 \%$ respecte a les dades que es disposen del $2010^{15}$. I cal pensar que la xifra encara pot ser molt més alta, tal com apuntava l'antro-

13. What has happened to suicides during the Greek economic crisis? Findings from an ecological study of suicides and their determinants (2003-2012): http://www.ncbi.nlm.nih.gov/pmc/articles/PMC4386238/.

14. L'Eurostat (en anglès: Statistical Office of the European Communities) és l'oficina estadística de la Comissió Europea: http://ec.europa.eu/eurostat.

15. "The impact of fiscal austerity on suicide: On the empirics of a modern Greek tragedy":

http://www.sciencedirect.com/science/article/pii/S0277953614002433 
pòleg Stanley Bradley en comentar les dades obtingudes en la seva recerca en un poble de Castella durant els anys 70: «Suïcidar-se és un crim tant estatal com religiós, i els que maten no tenen el dret d'ésser enterrats al Campo Santo. Reconèixer una fi com aquesta, no només seria condemnar l'ànima del finat, sinó influir eternament en la fama de la seva família. Per estalviar aquestes conseqüències, el poble segueix una norma molt coneguda a tota la Mediterrània, principalment a Itàlia on és anomenada omertà (Friedmann, 1967: 330); és a dir, davant el risc legal del món extern, el poble calla i es protegeix.» (1984: 38). I que l'hel-lenista Pedro Olalla també comentava en un article publicat al diari $\mathrm{La}$ Vanguardia ${ }^{16}$ i del que reprodueixo un fragment: «Pero, al margen de esto, sólo hace falta un dato para tomar conciencia suficiente de la tragedia: en los últimos cuatro años, más de 2.500 personas se han quitado la vida. Que se sepa; porque muchas familias lo ocultan por cuestiones de fe, por dolor, por vergüenza. Desde que empezó la "crisis" hasta hoy, más de una persona se ha suicidado cada día. No han sido sólo los suicidios del farmacéutico Dimitris Christoulas o del maestro Savvas Metikidis. Han sido cientos y cientos más, con nombres y apellidos, día tras día. Y hoy también habrá alguien que, privado de sentido y de esperanza, cogerá la escopeta, o la soga, o abrirá la ventana. Y mañana también, aunque no nos lo cuenten las noticias. Sólo esto, sólo esto debería bastar para demostrar y condenar el abominable fracaso".

Les conseqüències de les polítiques d'austeritat són palpables no només a Grècia, i l'augment dels suïcidis és l'indicador més cruel de fins on ens pot portar prioritzar les xifres per sobre del benestar de les persones.

\subsection{La reacció}

«La tradición dice que él (Tiako) decidió abandonar la tierra con todos los que quisieran seguirle y hacerse a la mar. Este es el modo tradicional de cometer suicidio en Tikopia, llevado a cabo por un grupo de personas, bien en protesta contra lo que consideran una falsa acusación, o bien cuando han cometido una ofensa contra un hombre de rango. Normalmente, cuando las pasiones no se han desatado hasta lo funesto, el viaje del suicida es interrunpido con un procedimiento formal por parte de algún otro miembro de

16. Más de 2.500 personas se han suicidado en Grecia desde el inicio de la crisis (30/4/13) http://www.lavanguardia. com/lectores-corresponsales/20130430/54371643910/2-500-suicidios-grecia-crisis.html 
la comunidad. Sin embargo, en este caso, el rencor y la codicia de tierras eran supremas, y ninguna mano se alzó para detener el curso de Nga Faea. El pueblo se marcho imponente» (Firth citat a Terradas 2008: 162)

L'any 2012 dins un context complex de retallades com el que he descrit anteriorment a Grècia, el moviments dels indignants sorgit a l'estat espanyol, arribà amb les seves peculiaritats al territori hel-lènic, on agafa dimensions considerable ${ }^{17}$. A Iràklion, els manifestants van ocupar la plaça Eleftheria, just al centre de la capital cretenca, i allà van establir, el seu campament base. Durant les assemblees sorgeix la idea entre un grup de ciutadans de crear davant la precària situació de la sanitat grega i el difícil accés de cada vegada més ciutadans a aquest dret, la creació de l'hospital social d'Iràklion. Una iniciativa encapçalada per la cèl·lula Mikis Theodorakis de $\mathrm{Creta}^{18}$, que dos de feia dos anys ja realitzava tasques d'assistència social a la capital cretenca, tal com mexplicava Dimitri, un dels seus membres. A partir d'aquest moment, la creació de l'hospital social d'Iraklion agrupa un nombre més gran de voluntaris on els metges tenen un paper prepondarant. Després de dos anys de realitzar tasques de suport a la ciutadania des d'emplaçaments diferents, l'any 2013 aconsegueixen instal-lar-se a les antigues instal-lacions de la universitat de Creta a Knossos. On des d'allà aconsegueixen organitzar amb l'ajuda de dos centenars de voluntaris i de forma assembleària, un centre d'assistència sanitària amb diferents especialitats: des d'oculistes a pediatres, passant per dentistes o psiquiatres. A més a més, el centre compte també amb una farmàcia autogestionada per un equip de farmacèutics, que funciona gràcies a l'aportació desinteressada de medicaments per part de ciutadans o de les donacions econòmiques que de forma anònima realitzen particulars ${ }^{19}$. En l'actualitat, l'hospital compte amb més de 2000 pacients, segons les dades que em van facilitar durant l'estiu de l'any 2015. I apart de la seva tasca assistencial, intenta a través de diferents mitjans conscienciar a la població dels efectes perversos que l'austeritat està ocasionant a la salut de les persones ${ }^{20}$.

17. Per què els grecs són a les places? (J. Alsina 2016: 76).

18. L'any 2011, el músic i compositor Mikis Theodorakis, va fer una crida a la societat civil grega perquè s'organitzés arreu del país davant l'embat el qual s'exposava i la fragilitat evident de l'estat grec.

19. Tal com he pogut observar en una de les assemblees internes on vaig poder participar. Són molts els pacients que depenen del bon funcionament del centre i del repartiment dels medicaments.

20. L'any 2015 van realitzar un documental titulat "L'austeritat: la medicina que mata", i que es pot veure subtitutal al castellà a la xarxa: https://www.youtube.com/watch?v=BleTZriYI90. 


\section{Conclusió}

Ens situem en un moment on es desproveeix a la població dels recursos normalitzats per desenvolupar les funcions assignades a l'entorn social propi. En termes vindicatoris parlaríem d'una ofensa sense possibilitat de compensació, és a dir, la població davant l'empenta neoliberal capitanejada pels mercats financers es troba en una situació clara d'indefensió, ja que al quedar-se sense els mitjans necessaris que garanteixin la seva supervivència amb dignitat (bé sigui perquè s'ha quedat sense feina, casa,...) es veu totalment orfe de justícia, davant un Dret, buit de principis ètics o morals, que sota el paraigües d'un sacralitzat positivisme obvia els seus principis més bàsics, on el mercat usa les seves "armes financeres de destrucció massiva”21, que inevitablement evoquen a una gran part de la població a una davallada de la seva esperança de vida i per conseqüència, el deteriorament físic o psíquic, que arribat als seus extrems porta al suïcidi. Ens trobem doncs, en una situació d'indefensió, davant la manca real de justícia: "En una democracia censitaria sólo los propietarios ejercen derechos como ciudadanos. En nuestras democracias sólo ciertos niveles de riqueza son capaces de obtener los contratos previos a la acción de la justicia en muchas materias, incluyendo varias penales. El imperio del mercado sobre lo jurídico hace que en general el derecho - por haberse privatizado en muchos casos su acceso- sea caro, y la justicia - por ser pública- mal pagada o bien pagada pero mal reconocida. El mercado está mucho más al servicio de lo culposo - por lo menos- que del cumplimiento: se desentiende de las consecuencias vitales de los contratos y así lo respetan la ley y la jurisprudencia en la medida en que toleran o ensalzan el mercado como fuente de derecho. El mercado puede alcanzar por la vía dolosa la disponibilidad de derechos fundamentales de las personas. Esto puede producir situaciones análogas a las de una sociedad de nobles y siervos." (Terradas 2008: 18).

Per tant, un cop ha quedat palès que com a conseqüència de les decisions preses per la Troika i les seves mesures d'austeritat es desplega un camp d'afectació total sobre la vida i la mort de les poblacions, només ens queda fonamentar en el Dret, que les seves accions no quedin impunes. Primerament des d'un punt de vista conceptual provinent de l'antropologia jurídica, és evident que aquestes polítiques el que fan es desproveir a la població dels recursos normalitzats per desenvolupar les funcions assignades per l'entorn

21. Segons la terminologia usada per Stiglitz i altres economistes afins (Hinkelemert: 2013). 
social. En el que qualifico, com ja he assenyalat anteriorment, com una ofensa sense possibilitat de compensació, pel fet de desproveir d'un teixit de suport secundari que pal-lii els efectes del primer desproveïment (tasca tradicional de l'Estat del Benestar, en procés de desmantellament).

L'anomia i el suïcidi, per tant, serien la conseqüència d'una doble absència: la del mercat, i la de l'Estat. Ambdós tradicionals proveïdors de mitjans per a la supervivència orgànica i social de les poblacions.

Per altra banda, les iniciatives com les de l'hospital social d'Iraklion, ens demostren un cop més, com la solidaritat és un dels mecanismes clàssics que hem fet servir els humans el llarg de la nostra història, per enfrontar-nos a diferents processos d'indefensió. Son diversos els estudis tant des de les ciències socials com les naturals, que ens demostren des de perspectives diferents (Clastres: 2009, Phillppe Descola: 1999), com en situació extremes i de màxima dificultat, els homínids, hem buscat al llarg de la nostra història i en cultures ben distants les unes de les altres, formes diverses de mostrar la solidaritat entre nosaltres, $\mathrm{i}$ com aquesta ha estat un element cabdal per a la nostra supervivència fins a l'actualitat ${ }^{22}$.

\section{Bilbiografia}

Alsina, Jordi (2016): (A)illat. Històries d'un nàufrag a Creta. Mataró: Edicions del Grhec. Clastres, Pierre (2009): Investigacions en antropología política. Barcelona: Gedisa. Descola, Philippe (2012): Más allà de naturaleza y cultura. Madrid: Amorrortu. Durkheim, Emile (1987). La división del trabajo social. Madrid: Akal.

Durkheim, Emile (1992). El suicidio. Madrid: Akal.

Krugman, Paul (2012): ¡Acabad ya con esta crisis!. Madrid: Editorial Crítica.

Lévi-Straus, Cl. Et al (1981): La identidad. Barcelona. Petrel.

22. Per contra de la imatge de la violència com element inherent a la condició humana els fonaments de la qual trobaríem en les ideologies racistes i eugenètiques del selge XIX. 
Madianós, Mixális G. ; Oikonómou, Maria (2014): Elliniki krisi, «ethniki» katastasi kai askiseis epibiosis (Crisi grega, depressió nacional i exercicis de supervivència). Atenes: Edicions Kastanioti.

Merton, Robert (2003): Teoria y estructura sociales. Madrid: Fondo de Cultura Económica.

Mills, Whright (1957): La elite del poder. Madrid: Fondo de Cultura Económica.

Stuckler, David; Basu, Sanjay (2013). The body economic: Why Austerity Kills. New York: Basic books.

Stiglitz, Joseph (2015): The Great Divide: unequal societies and what we can do about them. New York: Norton.

Terradas, Ignasi (2008): Justicia vindicatoria: de la ofensa e indefensión a la imprecación y el oráculo, la vindicta y el talión, la ordalía y el juramento, la composición y la reconciliación. Madrid: Consejo Superior de Investigaciones Científicas.

Todorov, Tzevan (1987): La conquista de América: el problema del otro. Buenos Aires: Siglo XXI.

\section{Revistes}

Brandes, Stanley (1984): Nombres que enganyen: cinc problemes en la interpretació de dades censals en l'Espanya rural. Quaderns de l'Institut Català d'Antropologia, 5:38-50.

Terradas, Ignasi (2012): "Què és la justícia vindicatòria? (Definició i característiques fonamentals)”. Recerques: Història, Economia i Cultura, 64: 13-30. 
Xedagogia i Treball Social

Revista de Ciències Socials Aplicades

Edita: Universitat de Girona

Disseny i maquetació: info@clam.cat · 647427732

Dipòsit Legal: GI.904-2010

ISSN: 2013-9063 